\title{
PENGEMBANGAN ALGORITMA STEMMING BAHASA INDONESIA DENGAN PENDEKATAN DICTIONARY BASE STEMMING UNTUK MENENTUKAN KATA DASAR DARI KATA YANG BERIMBUHAN
}

\author{
Ahmad Fikri Zulfikar \\ Teknik Informatika, Fakultas Teknik, Universitas Pamulang \\ Email: dosen00386@unpam.ac.id
}

\begin{abstract}
ABSTRAK
Information Retrieval adalah studi tentang sistem pengindeksan, pencarian, dan mengingat data, khususnya teks atau bentuk tidak teratur lainnya. Pada proses tahap indexing didalam information retrieval terdapat proses stemming yaitu proses mengubah suatu kata bentukan menjadi kata dasar. Proses stemming sangat tergantung kepada bahasa dari kata yang akan di stemm. Hal ini dikarnakan, dalam melakukan proses stemming harus mengaplikasikan aturan morfologikal dari suatu bahasa. Bahasa Indonesia memiliki kata berimbuhan yang lebih kompleks dibandingkan dengan Bahasa Lainnya. Terdapat dua pendekatan dalam proses stemming yaitu: Light Stemming dan Dictionary Base Stemming. pendekatan dengan proses Dictionary Base Stemming dapat memberikan solusi untuk men-stemm kata berimbuhan dalam Bahasa Indonesia, karena menggunakan struktur morfologi untuk mengekstrak kata berimbuhan menjadi kata dasar (root word). pada penelitian ini akan menggunakan pendekatan proses Dictionary Base Stemming untuk mengembangkan Algoritma Stemming Bahasa Indonesia dalam menentukan kata dasar (root word) pada kata yang berimbuhan dengan Metode Pengembangan Sistem OOAD.
\end{abstract}

Kata kunci: Information Retrieval, Stemming, Dictionary Base, Bahasa Indonesia, dan OOAD

\section{PENDAHULUAN}

Untuk proses stemming Bahasa Indonesia ini sebelumnya sudah pernah diteliti oleh beberapa peneliti diantaranya: Algoritma Stemming Nazief \& Andriani, Algoritma Stemming Arifin \& Setiono dan Algortima Stemming Vegas (Asian \& Williams, 2005, p. 2).

Dari pernyataan diatas, pendekatan dengan proses Dictionary Base Stemming dapat memberikan solusi untuk men-stemm kata berimbuhan dalam Bahasa Indonesia, karena menggunakan struktur morfologi untuk mengekstrak kata berimbuhan menjadi kata dasar (root word).

Pada penelitian ini penulis akan menggunakan pendekatan proses Dictionary Base Stemming untuk mengembangkan Algoritma Stemming Bahasa Indonesia dalam menentukan kata dasar (root word) pada kata yang berimbuhan.

\section{MASALAH}

a. Bahasa Indonesia memiliki kata berimbuhan yang kompleks dibandingkan dengan bahasa yang lainya, karena memiliki imbuhan yang variatif seperti prefiks (awalan), sufiks (akhiran), konfiks (kombinasi awalan-akhiran), dan infiks (sisipan).

b. Belum adanya aplikasi prototype untuk menguji ketepatan penentuan kata dasar (root word) dari kata berimbuhan yang Berbahasa Indonesia.

\section{METODE PENELITIAN}

Pada tahap ini dibahas tentang perancangan sistem stemming Bahasa Indonesia menggunakan pendekatan Dictionary Base Stemming dengan model pengembangan sistem Object Orientied Analys Design (OOAD) dengan notasi Unified Modeling Language (UML) yang terdiri dari Activity Diagram, Use Case Diagram, Class Diagram, dan Sequence Diagram.

a. Activity Diagram 


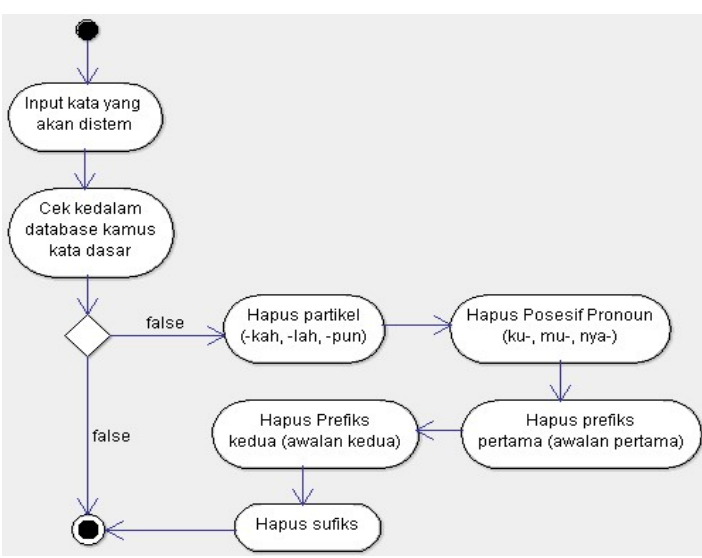

b. Usecase Diagram

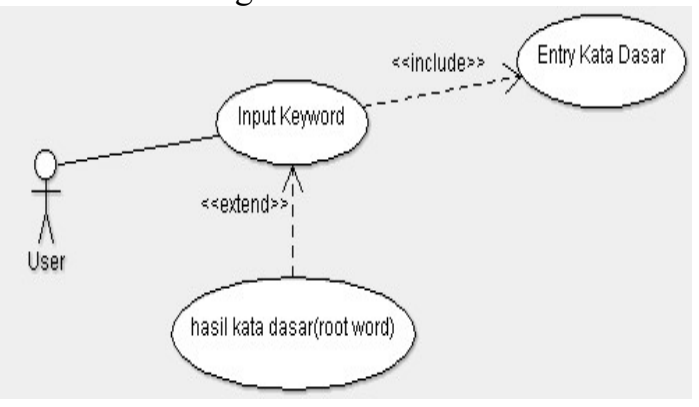

\section{TEKNIK ANALISA DATA}

Data yang digunakan adalah aturan morfologi imbuhan Bahasa Indonesia yang dikumpulkan penulis dari beberapa buku tentang bahasa indonesia, antara lain:

a. Buku Tata Bahasa Baku Bahasa Indonesia (Alwi, 1998, p. 78)

b. Pembentukan kata Bahasa Indonesia (Kridalaksana, 1996, pp. 98-106)

Kamus yang dugunakan dalam algoritma stemming ini, adalah kamus kumpulan kata dasar Bahasa Indonesia yang diambil dari kamus elektronik Bahasa Indonesia-Inggris dan kamus elektronik Bahasa Indonesia-Belanda. Dengan dibuatkan aplikasi sederhana untuk proses stemming Bahasa Indonesia, dapat ditentukan ketepatan dalam menentukan kata dasar dari kata yang berimbuhan dengan menggunakan pendekatan dictionary base stemming.

Berikut ini adalah rancangan table hasil algoritma stemmer tersebut:

Tabel 15 Rancangan Tabel Hasil Uji Coba stemming

\begin{tabular}{|c|c|c|c|c|c|c|c|}
\hline No. & Inputan & $\begin{array}{c}\text { Hapus } \\
\text { partikel }\end{array}$ & $\begin{array}{c}\text { Hapus } \\
\text { PP }\end{array}$ & $\begin{array}{c}\text { Hapus } \\
\text { awalan 1 }\end{array}$ & $\begin{array}{c}\text { Hapus } \\
\text { awalan 2 }\end{array}$ & $\begin{array}{c}\text { Hapus } \\
\text { Akhiran }\end{array}$ & $\begin{array}{c}\text { Kata } \\
\text { dasar }\end{array}$ \\
\hline 99 & $\mathrm{x}-30 \mathrm{x}$ & $\mathrm{x}-30 \mathrm{x}$ & $\mathrm{x}-30 \mathrm{x}$ & $\mathrm{x}-30 \mathrm{x}$ & $\mathrm{x}-30 \mathrm{x}$ & $\mathrm{x}-30 \mathrm{x}$ & $\mathrm{x}-30 \mathrm{x}$ \\
\hline 99 & $\mathrm{x}-30 \mathrm{x}$ & $\mathrm{x}-30 \mathrm{x}$ & $\mathrm{x}-30 \mathrm{x}$ & $\mathrm{x}-30 \mathrm{x}$ & $\mathrm{x}-30 \mathrm{x}$ & $\mathrm{x}-30 \mathrm{x}$ & $\mathrm{x}-30 \mathrm{x}$ \\
\hline
\end{tabular}

Tabel 16 Rancangan Tabel Hasil Validasi

\begin{tabular}{|l|l|l|}
\hline $\begin{array}{c}\text { Stemming } \\
\text { Stemmer }\end{array}$ & Total & Persentase(\%) \\
\hline $\mathrm{x}-30-\mathrm{x}$ & 99 & $99 \%$ \\
\hline $\mathrm{x}-30-\mathrm{x}$ & 99 & $99 \%$ \\
\hline
\end{tabular}

\section{TEKNIK ANALISIS PENGGUNAAN METODE DALAM SISTEM}

Pada teknik penggunaan metode dalam sistem ini berisi tentang metode-metode yang diterapkan dalam proses stemming Bahasa Indonesia untuk menentukan kata dasar dari kata yang berimbuhan (Alhanin \& Juzaiddin, 2011).

a. Metode Dictionary Base Stemming adalah pendekatan struktur morfologi pada suatu bahasa yang terdapat aturan imbuhan untuk mengekstrak kata dasar. Pola aturan imbuhan pada Bahasa Indonesia dalam berbagai variatif seperti prefiks, sufiks, konfiks, dan infiks dengan segmentasi sebagai berikut:

Tabel 3 Kombinasi Aturan Awalan-Akhiran

\begin{tabular}{|l|l|}
\hline Awalan & Akhiran yang tidak diizinkan \\
\hline be- & $-\mathrm{i}$ \\
\hline di- & -an \\
\hline ke- & $-\mathrm{i}$, -kan \\
\hline me- & -an \\
\hline se- & -i, -kan \\
\hline
\end{tabular}


Tabel 4 Cara menentukan tipe awalan te-

\begin{tabular}{|c|c|c|c|c|}
\hline \multicolumn{4}{|c|}{ Following Characters } & \multirow{2}{*}{ Tipe Awalan } \\
\hline Set 1 & Set 2 & Set 3 & Set 4 & \\
\hline "-r-" " & "-r-r"“ & - & - & None \\
\hline "-r-" & & - & - & ter-luluh \\
\hline "-r-" & not (vowel or “-r-") & "'-er-" & vowel & Ter \\
\hline "-r-"“" & not (vowel or "-r-") & “"-er-"“ & not vowel & ter- \\
\hline "-r-r" & not (vowel or "-r-") & not "-er-" & - & Ter \\
\hline not (vowel or "-r-") & "-er-" & Vowel & - & None \\
\hline not (vowel or "-r-") & "-er-" & not vowel & - & $\mathrm{Te}$ \\
\hline
\end{tabular}

Tabel 5 Jenis Awalan berdasarkan tipe awalannya

\begin{tabular}{|l|l|}
\hline Tipe Awalan & Awalan yang harus dihapus \\
\hline di- & di- \\
\hline ke- & ke- \\
\hline se- & se- \\
\hline te- & te- \\
\hline ter- & ter- \\
\hline ter-luluh & Ter \\
\hline
\end{tabular}

Tata Cara Pengoprasian Program
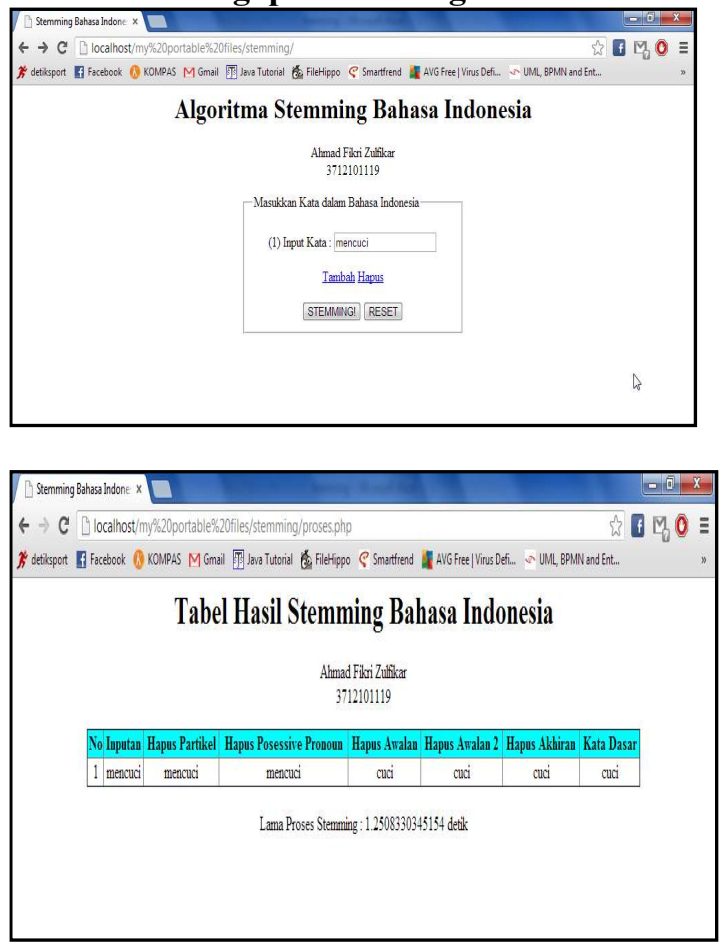

\section{PEMBAHASAN}

Hasil table uji coba dari 30 kata yang berimbuhan yang diproses oleh algoritma Stemming Bahasa Indonesia dengan pendekatan Dictionary Base Stemming ditunjukkan pada Tabel 6.

\section{KESIMPULAN}

Berdasarkan hasil penelitian dan pembahasan yang disampaikan pada bagian sebelumnya, maka dapat ditarik beberapa kesimpulan seperti berikut:

a. Implementasi dengan pendekatan Dictionary Base Stemming Bahasa Indonesia untuk menentukan kata dasar (root word) dari kata berimbuhan yang bervariatif seperti: prefiks, sufiks, infiks, dan konfiks, cukup memuaskan dilihat dari hasil uji coba dengan 30 sempel kata berimbuhan Bahasa Indonesia yang sudah ditentukan oleh penulis, dimana katagori dari hasil stemmer Exact Match nilai presentasenya sebesar $93.3 \%$ (persen), sedangkan katagori hasil stemmer Unchange nilai presentasenya mencapai $6.7 \%$ (persen) dikarnakan ketidaktepatan dalam melakukan proses pemenggalan kata yang berulang-ulang, dan katagori hasil stemmer Spelling Exception nilai presentasenya 0\% (persen).

b. Analisis dan desain sistem pada proses Algoritma Stemming Bahasa Indonesia ini dilakukan dengan menggunakan metodologi $O O A D$ yang dijabarkan menjadi empat tahap yaitu definisi kebutuhan, perancangan sistem, implementasi serta integrasi dan pengujian sistem. Pada tahap definisi kebutuhan Algoritma Stemming Bahasa Indonesia dibutuhkan dan diaplikasikan dibidang information retrieval system (infromasi sistem temu kembali) dan komputasi linguistic. Pada tahap perancangan ini menggunakan model diagram UML (Unified Modeling Language) yang terdiri dari activity diagram, use case diagram, class diagram, sequence diagram, deploypment diagram dan component diagram. Tahap implementasi, Sistem untuk proses stemming ini berbasis web dengan 
menggunakan bahasa PHP dan database MySQL. Untuk tahap terakhir yaitu integrasi dan pengujian sistem, sistem yang dibangun diuji dengan menggunakan metode pengujian White Box dan Black Box.

Tabel 6 Hasil Tabel Uji Coba

\begin{tabular}{|c|c|c|c|c|c|c|c|c|}
\hline & Inputan & $\begin{array}{c}\text { Hapus } \\
\text { partikel }\end{array}$ & Hapus PP & $\begin{array}{c}\text { Hapus } \\
\text { prefiks } 1\end{array}$ & $\begin{array}{c}\text { Hapus } \\
\text { prefiks } 2\end{array}$ & $\begin{array}{l}\text { Hapus } \\
\text { sufiks }\end{array}$ & Kata dasar & $\begin{array}{c}\text { Katagori } \\
\text { hasil }\end{array}$ \\
\hline 1 & Merupkan & Merupakan & Merupakan & Rupkan & Rupakan & Rupa & Rupa & Exact Match \\
\hline 2 & Menyapu & Menyapu & Menyapu & Sapu & Sapu & Sapu & Sapu & Exact Match \\
\hline 3 & Bermain & Bermain & Bermain & Bermain & Main & Main & Main & Exact Match \\
\hline 4 & Permainan & Permainan & Permainan & Permainan & Mainan & Main & Main & Exact Match \\
\hline 5 & Menyiapkan & Menyiapkan & Menyiapkan & Siapkan & Siapkan & Siap & Siap & Exact Match \\
\hline 6 & Mencuci & Mencuci & Mencuci & Cuci & Cuci & Cuci & Cuci & Exact Match \\
\hline 7 & Belajar & Belajar & Belajar & Belajar & Ajar & Ajar & Ajar & Exact Match \\
\hline 8 & Pelari & Pelari & Pelari & Pelari & Lari & Lari & Lari & Exact Match \\
\hline 9 & Mencintai & Mencitai & Mencintai & Cintai & Cintai & Cinta & Cinta & Exact Match \\
\hline 10 & Penyayang & Penyayang & Penyayang & Sayang & Sayang & Sayang & Sayang & Exact Match \\
\hline 11 & Laki-laki & Laki-laki & Laki-laki & Laki-laki & Laki-laki & Laki-lak & Laki-lak & Unchange \\
\hline 12 & Mempunyai & Mempunyai & Mempunyai & Punyai & Punyai & Punya & Punya & Exact Match \\
\hline 13 & Melahirkan & Melahirkan & Melahirkan & Lahirkan & Lahirkan & Lahir & Lahir & Exact Match \\
\hline 14 & Melupakan & Melupakan & Melupakan & Lupakan & Lupakan & Lupa & Lupa & Exact Match \\
\hline 15 & Melakukan & Melakukan & Melakukan & Lakukan & Lakukan & Laku & Laku & Exact Match \\
\hline 16 & Melukai & Melukai & Melukai & Lukai & Lukai & Luka & Luka & Exact Match \\
\hline 17 & Terlupakan & Terlupakan & Terlupakan & Lupakan & Lupakan & Lupa & Lupa & Exact Match \\
\hline 18 & Terlewatkan & Terlewatkan & Terlewatkan & Lewatkan & Lewatkan & Lewat & Lewat & Exact Match \\
\hline 19 & Berkelahi & Berkelahi & Berkelahi & Berkelahi & Kelahi & Kelahi & Kelahi & Exact Match \\
\hline 20 & Mewarnai & Mewarnai & Mewarnai & Wrnai & Warnai & Warna & Warna & Exact Match \\
\hline 21 & Menentukan & Menetukan & Menentukan & Tentukan & Tentukan & Tentu & Tentu & Exact Match \\
\hline 22 & Menentang & Menentang & Menentang & Tentang & Tentang & Tentang & Tentang & Exact Match \\
\hline 23 & Bernyanyi & Bernyanyi & Bernyanyi & Bernyanyi & Nyanyi & Nyanyi & Nyanyi & Exact Match \\
\hline 24 & Mencaci & Mencaci & Mencaci & Caci & Caci & Caci & Caci & Exact Match \\
\hline 25 & Berlabuh & Berlabuh & Berlabuh & Berlabuh & Labuh & Labuh & Labuh & Exact Match \\
\hline 26 & Bertikai & Bertikai & Bertikai & Bertikai & Tikai & Tikai & Tikai & Exact Match \\
\hline 27 & Menjuarai & Menjuarai & Menjuarai & Juarai & Juarai & Juara & Juara & Exact Match \\
\hline 28 & Majalah & Majalah & Majalah & Majalah & Majalah & Majalah & Majalah & Exact Match \\
\hline 29 & Abu-abu & Abu-abu & Abu-abu & Abu-abu & Abu-abu & Abu-abu & Abu-abu & Unchange \\
\hline 30 & Masalah & Masalah & Masalah & Masalah & Masalah & Masalah & Masalah & Exact Match \\
\hline
\end{tabular}

\section{DAFTAR PUSTAKA}

Adriani, M., Nazief, B., Asian, J., \& Williams, H. E. (2007). Stemming Indonesia A Confixs Stripping Approach. ACMTransactions on Asian Language Information Processing, Vol. 6, No. 4, 13.

Agusta, L. (2009). Comparasi Algoritma Stemming Porter dengan Algoritma Nazief dan Andriani untuk Stemming Dokumen Teks Bahasa Indonesia. Konfrensi Nasional Sistem dan Informatika. Bali.

Alhanin, Y., \& Juzaiddin, M. (2011). The Enhancement of Arabic Stemming by Using Light Stemming and Dictionary-Based Stemming. Journal of Software Engineering and Applications.

Alwi, H. (1998). Tata Bahasa Baku Bahasa Indonesia. Balai Pustaka.

Arifin, A. Z., \& Setiono, A. N. (2002). Klasifikasi Dokumen Berita Kejadian Berbahasa Indoensia dengan Algoritma Single Pass Clustering. www.its.ac.id.

Asian, J., \& Williams, H. E. (2005). Stemming Indonesia. Australia Computer Science Conference.
Bernstein, A., \& Kiefer, C. (2005). Imprecise Queries Using Similarity Joins For Retrieval in Ontologis. $i R D Q L$. Winterthurerstr: University Of Zurich.

Fachrurrozi. (2006). Algoritma dan Pemrograman I. Garfield, E. (1997). A Tribute To Calvin N. Mooers, A Pioneer Of Information Retrieval. The Scientist.

Kridalaksana, H. (1996). Pembentukan Kata Dalam Bahasa Indonesia. Gramedia.

Mandala, R., \& Munir, R. (2004). Sistem Stemming Otomatis untuk kata dalam Bahasa Indonesia. Seminar Nasional Aplikasi Teknologi Informasi. Yogyakarta.

O'Docherty, M. (2005). Object Oriented Anlayst and Design .

Pressman, R. (2010). Software Engineering : A Practitioner's Approach. Mc Grew-Hill Companies.

Prof. DR. Sugiyono. (2012). Metode Penelitian Kuantitatif, Kualitatif dan $R \& D$. Alfabeta.

Sommerville, I. (2011). Software Engineering. Pearson Education. 